\title{
Sistem Informasi Manajemen Pos Pelayanan Terpadu Kesehatan Jiwa Di Desa Bongkot
}

\author{
Athi’ Linda Yani', Mohamad Ali Murtadho \\ Universitas Pesantren Tinggi Darul Ulum Jombang ${ }^{1,2}$ \\ athilindayani@ fik.unipdu.ac.id", alimurtadho@ fik.unipdu.ac.id
}

\begin{abstract}
Bongkot village has many people suffering from mental disorders. There are around fifty people suffering from mental disorders. Prediction of mental disorders at table three is usually done through interviews. Cadres need to fill out the form provided on the Towards Healthy Soul Card (KMSJ) at the interview. The form needs to be filled out based on the results of the interview to predict whether the interviewee has a mental illness or not. If the results of the interview are predicted to have a mental disorder, the cadre will recommend appropriate follow-up. This process is certainly prone to mistakes because it only depends on cadre knowledge. Predictions will certainly affect the recommendations given. in this community service program, the authors propose to apply Information Technology (IT) to reduce the risk of such errors. The system is named the Mental Health Posyandu Management Information System (SIM). The system is expected to be able to improve the efficiency and effectiveness of services at the posyandu, the output of this service produces an online-based application related to the service of mental health posyandu with the address www. poskeswa.com.
\end{abstract}

Keywords: Health; Mental; SIM; Posyandu.

\begin{abstract}
Abstrak
Desa Bongkot merupakan sebuah desa yang warganya banyak menderita gangguang jiwa. Tercatat sekitar lima puluh warga menderita gangguan jiwa. Posyandu kesehatan jiwa merupakan pelayanan yang diselenggarakan oleh desa untuk menangani Orang Dengan Gangguan Jiwa (ODGJ) di Desa Bongkot. Pelayanan di Posyandu kesehawatan jiwa Desa Bongkot ini terdiri dari lima kegiatan yang ditandai dengan adanya lima meja pelayanan. Prediksi gangguan jiwa di meja tiga biasanya dilakukan melalui wawancara. Kader perlu mengisi formulir yang disediakan di Kartu Menuju Sehat Jiwa (KMSJ) pada saat wawancara. Formulir tersebut perlu diisi berdasarkan hasil wawancara untuk memprediksi apakah orang yang diwawancara menderita gangguan jiwa atau tidak. Bila dari hasil wawancara diprediksi mengalami gangguan jiwa, maka kader akan merekomendasikan tindak lanjut yang tepat. Proses ini tentu saja rawan kekeliruan karena hanya bergantung pada pengetahuan kader. Kekeliruan prediksi tentu akan mempengaruhi rekomendasi yang diberikan. Oleh sebab itu, dalam program pengabdian masyarakat ini, penulis mengusulkan untuk menerapkan Information Technology (IT) atau Teknologi Informasi untuk mengurangi resiko kekeliruan tersebut. Sistem tersebut diberi nama Sistem Informasi Manajemen (SIM) Posyandu Kesehatan Jiwa. Sistem tersebut diharapkan mampu meningkatkan efisiensi dan efektifitas pelayanan di posyandu, luaran dari pengabdian ini menghasilkan sebuah aplikasi berbasis online terkait pelayanan posyandu kesehatan jiwa dengan alamat www. poskeswa.com
\end{abstract}

Kata Kunci: Kesehatan; Jiwa; SIM; Posyandu. 


\section{A. PENDAhuluan}

Desa Bongkot adalah sebuah desa di Kecamatan Peterongan Kabupaten Jombang. Desa tersebut terkenal dengan jumlah warganya yang banyak menderita gangguan jiwa. Saat ini, tercatat ada sekitar 150 warga pernah mengalami gangguan jiwa. Seratus di antaranya telah dinyatakan bebas dari gangguan jiwa dan hidup selayaknya manusia pada umumnya. Sedangkan sekitar 50 sisanya masih dalam status rehabilitasi.

Pos Pelayanan Terpadu (Posyandu) kesehatan jiwa atau yang lebih dikenal dengan sebutan Posyandu Jiwa yang dibahas dalam program ini berkantor di Balai Desa Bongkot dan bernama "Posyandu Kesehatan Jiwa Pelita Harapan". Di Jombang, hanya ada beberapa posyandu yang menangani ODGJ. Posyandu Jiwa "Pelita Harapan" ini adalah posyandu yang paling mendapat perhatian dari pemerintah Jombang. Posyandu Jiwa Desa Bongkot diketuai oleh Ibu Nur Wahyuningrum, seorang kader yang berasal dari Desa Bongkot sendiri. Kegiatan pelayanan biasanya dilaksanakan pada hari Kamis minggu ke-3 pada tiap bulan. Sumber dana kegiatan Posyandu Jiwa berasal dari donatur warga. Saat ini, Posyandu Jiwa Desa Bongkot memiliki kader berjumlah empat puluh orang. Mereka merupakan relawan yang tidak memperoleh honor. Mereka bekerja demi misi kemanusiaan dan prihatin dengan kondisi tetangganya yang menjadi ODGJ. Selain kader, kegiatan Posyandu Jiwa juga dibantu oleh petugas kesehatan jiwa dari puskesmas pembantu terdekat. Namun jumlahnya hanya sekitar lima orang.

Kegiatan pelayanan di Posyandu Jiwa Desa Bongkot secara garis besar dapat dirangkum menjadi lima kegiatan utama yaitu pemeriksaan fisik, farmaka, konseling, pelatihan keterampilan hidup, dan pelatihan kemandirian hidup seperti berwirausaha.
Sehingga kader menyediakan lima meja pada saat pelaksanaan posyandu.

Kegiatan Posyandu Jiwa: Meja 1, pasien poyandu jiwa datang ke meja 1 dan mengantri untuk dicatat di buku daftar presensi. Setelah itu ia ditimbang dan diukur berat dan tinggi badannya. Data tersebut dicatat di buku Kartu Menuju Sehat Jiwa (KMSJ) yang disimpan oleh kader kesehatan jiwa di kantor desa. Tiap pasien memiliki KMSJ. Sehingga kader perlu mencari KMSJ yang sesuai dengan nama peserta terlebih dahulu sebelum data dicatat. Meja 2, pasien ODGJ diberi vitamin dan obat sesuai kebutuhan. Data pemberian vitamin dan obat itu pun perlu dicatat di buku KMSJ sebagai riwayat pengobatan atau riwayat kesehatan. Meja 3, pasien diminta untuk menuju meja 3 yang merupakan tempat untuk konseling terkait kesehatan jiwa. Kader akan mewawancarai pasien dengan beberapa pertanyaan yang sudah disediakan di buku KMSJ seperti apakah ia sulit tidur, apakah jantungnya berdebar-debar, apakah merasa melihat atau mendengar bisikan-bisikan, apakah merasa seperti malaikat, dan lain sebagainya. Dari wawancara ini, kader dengan dibantu petugas dari puskesmas pembantu akan memprediksi apakah pasien masih mengalami gangguan kejiwaan atau tidak. Jika masih mengalami gangguan jiwa, maka perlu ditentukan jenis gangguannya dan prioritas gangguan yang perlu ditangani. Setiap jenis gangguan jiwa memiliki ciri-ciri tersendiri. Satu ODGJ bisa saja menderita lebih dari satu macam gangguan jiwa. Akan tetapi jenis gangguan jiwa yang dapat dideteksi dari proses di Meja 3 ini hanya ada lima. Padahal sebenarnya terdapat lebih banyak gangguan jiwa (Yusuf, 2015). Meja 4, setelah selesai dari meja konseling atau meja 3, pasien ODGJ akan dilatih tentang keterampilan hidup. Terdapat tiga materi utama yaitu materi keterampilan merawat 
diri, keterampilan aktifitas sehari-hari, dan keterampilan berhubungan atau komunikasi. ODGJ pada umumnya terlihat tidak terawat, rambut berantakan, kulit kusam, baju compang-camping, dan bau tidak sedap. Di meja 4 ini, mereka akan diajari untuk tidak lagi berpenampilan seperti itu. Setelah diajari, mereka juga akan diberi tugas aktifitas sehari-hari yang selanjutnya tugas tersebut akan ditanyakan di saat pelaksanaan posyandu berikutnya. Meja 5, selain mampu menjalani hidup selayaknya manusia pada umumnya, ODGJ juga diharapkan untuk bisa mandiri dalam hidupnya. Sehingga selanjutnya ia dapat dikatakan bebas dari resiko gangguan jiwa. Oleh sebab itu, di meja 5 ini pasien ODGJ diberi pelatihan keterampilan untuk dapat hidup mandiri secara ekonomi seperti membuat kerajinan tas, keset, bros, dan lain-lain. Dokumentasi pelatihan keterampilan wirausaha di Meja 5 dapat dilihat pada Gambar 4. Jenis pelatihannya dicatat di buku KMSJ. Hasil penilaian kemampuan pasien dalam pelatihan kemandirian juga dicatat di KMSJ. Hasil dari keterampilan mereka juga dipasarkan oleh kader. Banyaknya pasien ODGJ yang perlu dilayani, juga merupakan permasalahan tersendiri bila riwayat kesehatan ODJ masih disimpan dalam bentuk buku. Kader perlu mencari di tumpukan KMSJ, membaca nama di halaman depan satupersatu dan pasien mengantri. Bila terlalu lama mengantri, pasien ODGJ beresiko untuk mengamuk karena mereka pada umumnya memiliki emosi yang kurang stabil.

Prediksi jenis gangguan dan tindakan juga masih terbatas pada lima jenis gangguan saja. Hal itu terjadi karena KMSJ didesain tidak terlalu banyak halaman agar kader mudah membacanya. Namun, hasil prediksi gangguan dan rekomendasi tindakannya pun terbatas pada lima jenis gangguan saja.
Padahal, gangguan jiwa tidak hanya ada lima jenis saja, tetapi sangat banyak (Yusuf, 2015).

Oleh sebab itu, dibutuhkan suatu Sistem Informasi Manajemen (SIM) yang dapat meningkatkan efektifitas dan efisiensi pelayanan di posyandu sehingga permasalahan yang telah diuraikan di atas dapat teratasi (Mulyani, 2015). Sistem informasi manajemen posyandu telah banyak dibuat. Namun, sebagian besar berfokus pada posyandu balita (Sholihah, 2015). Belum ada SIM yang dibangun untuk posyandu kesehatan jiwa. Padahal kedua posyandu ini memiliki perbedaan dari sisi alur prosesnya.

Pada kegiatan ini, tim pengabdian masyarakat mengusulkan untuk membuat sistem yang diharapkan mampu mengelola data posyandu dengan lebih efektif dari pada KMSJ. Mulai dari mencatat kehadiran, mencari data pasien, menyimpan riwayat pemberian obat dan vitamin, menyimpan data tindakan medis, menyimpan data status keterampilan hidup, keterampilan kemandirian hidup pasien ODGJ, menyimpan jenis gangguan jiwa lebih banyak dari KMSJ, mengadopsi ilmu diagnosis kesehatan jiwa untuk memprediksi jenis gangguan jiwa, dan mampu memberikan rekomendasi yang lebih bervariasi berdasarkan jenis gangguan. Selain itu, sistem tersebut juga dapat digunakan sebagai media untuk promosi hasil kerajinan ODGJ yang selama ini masih belum terpublikasikan dengan baik. 


\section{B. PELAKSAAAN DAN METODE}

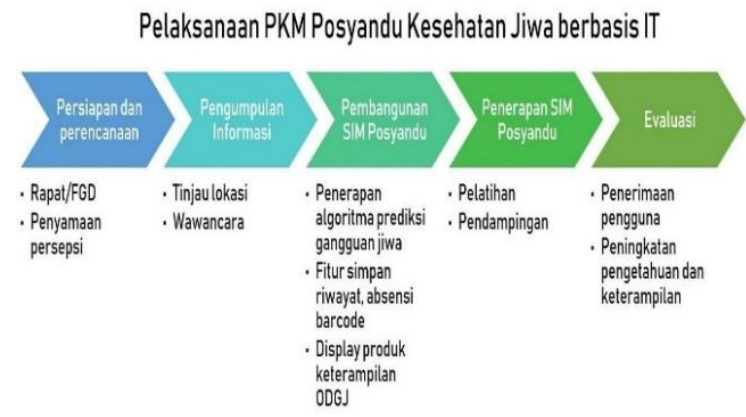

Gambar 1. Langkah-langkah pelaksanaan program pengabdian Posyandu Kesehatan Jiwa berbasis IT.

Kegiatan yang diusulkan pada program ini secara umum dibagi menjadi dua tahapan utama yaitu pembuatan sistem informasi manajemen dan pelatihan penggunaan SIM kepada kader-kader posyandu. Dua kegiatan tersebut selanjutnya dipisah lagi menjadi lima kegiatan. Berikut rincian rencana pelaksanaan program pengabdian masyarakat Posyandu Jiwa Pelita Harapan.

Persiapan dan perencanaan, proses ini bertujuan untuk mengidentifikasi masalahmasalah apa saja yang dialami oleh mitra. Selain itu, kegiatan ini juga bertujuan untuk menyamakan persepsi tentang program pengabdian yang akan dilaksanakan oleh tim, sehingga nantinya tidak ada kesalah-pahaman terkait apa yang menjadi kewajiban dan hak tim abdimas mau pun mitra. Persiapan dan perencanaan berupa rapat atau Focus Group Discussion (FGD) antara mitra dengan tim pelaksana pengabdian.

Pengumpulan informasi, kegiatan ini bertujuan untuk memperoleh informasi tentang proses atau alur bisnis posyandu dan memperkirakan masalah-masalah apa saja yang akan timbul jika SIM Posyandu yang diusulkan diterapkan. Informasi yang didapat selanjutnya akan dibahas lebih lanjut sabagai bahan untuk menentukan fitur-fitur apa saja yang perlu ada di SIM Posyandu Jiwa.
Pembuatan SIM Posyandu Kesehatan Jiwa, proses ini direncanakan akan dikerjakan dalam waktu tiga bulan. Pembuatan SIM Posyandu meliputi pendefinisian kebutuhan fungsional dan non-fungsional, perancangan, coding atau scripting, dan pengujian. Di setiap bulan, tim pelaksana dan mitra akan mengadakan diskusi grup untuk melaporkan progres pembuatan SIM. Diskusi tersebut juga bertujuan untuk memeriksa apakah yang sudah dikerjakan sudah sesuai dengan kebutuhan mitra.

Penerapan SIM Posyandu Kesehatan Jiwa, proses penerapan membutuhkan persiapan terlebih dahulu. Khususnya menyiapkan perangkat IT untuk SIM Posyandu. Setelah perangkat IT siap, tim pelaksana akan mengadakan acara launching atau peluncuran sistem informasi. Kegiatan selanjutnya adalah menyiapkan sumber daya manusia pengguna sistem yaitu dengan cara pelatihan. Pelatihan akan diadakan untuk membuat kader-kader mengetahui langkahlangkah menggunakan SIM Posyandu. Selain itu, kader juga harus mampu mengoperasikan SIM Posyandu agar nantinya dapat langsung menggunakannya saat posyandu berlangsung. Setelah mendapat pelatihan, kader dihimbau untuk mengajari keluarga pasien bagaimana cara mengakses SIM Posyandu untuk melihat riwayat kesehatan anggota keluarganya yang termasuk pasien posyandu jiwa. Selain pelatihan, tim pelaksana pengabdian juga akan melakukan pendampingan penggunaan SIM Posyandu sebagai pendukung pelayanan selama dua kali posyandu.

Evaluasi, kegiatan ini bertujuan untuk memperoleh informasi apakah SIM Posyandu telah dapat diterima oleh penggunanya atau tidak. Evaluasi juga diperlukan untuk memastikan apakah terdapat peningkatan pengetahuan dan keterampilan kader dalam memanfaatkan teknologi informasi untuk pelayanan posyandu yaitu SIM Posyandu 
Jiwa. Evaluasi dilakukan dengan cara menyebarkan kuisioner ke kader dan juga keluarga pasien selaku pengguna SIM Posyandu.

\section{HASIL DAN PEMBAHASAN}

Aplikasi SIM posyandu kesehatan jiwa dibuat agar lebih efesien dan memudahkan kader dalam proses pendokumentasian data pasien. Sebelumnya pada aplikasi ini telah dilakukan beberapa kali uji coba untuk input data pasien, setelah hasil data yang diperoleh valid dan aplikasi dapat diakses secara online tim abdimas datang ke lokasi mitra untuk koordinasi terkait sosialisasi dan launcing penerapan apilasi SIM posyandu kesehatan jiwa di desa bongkot. Mitra sangat merespon baik dan antusias terkait progam baru posyandu kesehatan jiwa yang berbasis IT, progam ini merupakan satu-satunya progam yang ada di posyandu jiwa bongkot. Sesuai dengan rencana kegiatan yang sudah dibuat oleh tim abdimas. Pelaksanaan progam kemitraan masyarakat di Desa Bongkot dilakukan menjadi empat tahapan.

\section{Sosialisasi dan launcing progam SIM posyandu kesehatan jiwa}

Pelaksanaan kegiatan tersebut dilakukan pada tanggal 8 Juli 2019, tim abdimas melakukan koordinasi dengan mitra terkait rencana jadwal kegiatan dan persiapan lokasi. Pada kegiatan sosialisasi tim abdimas mengundang seluruh kader posyandu jiwa yang berjumlah 45 orang, pihak puskesmas, dan perangkat desa setempat. Sebelum melakukan sosialisasi tim abdimas membagikan kuesioner kepada seluruh kader terkait pengetahuan terhadap SIM posyandu kesehatan jiwa. Setelah kader mengisi semua kuesioner tim abdimas memulai sosialisasi tentang SIM posyandu kesehatan jiwa. Tim abdimas menjelaskan bagaimana proses login dan cara memasukan data pasien sampai dengan melihat hasil rekam medis. Semua kader bahkan kepala pukesmas yang hadir dalam kegiatan juga ikut mencoba aplikasi tersebut, karena aplikasi ini dapat diakses secara online. Hasil luaran yang dicapai dari aplikasi Sistem Informasi Manajemen.

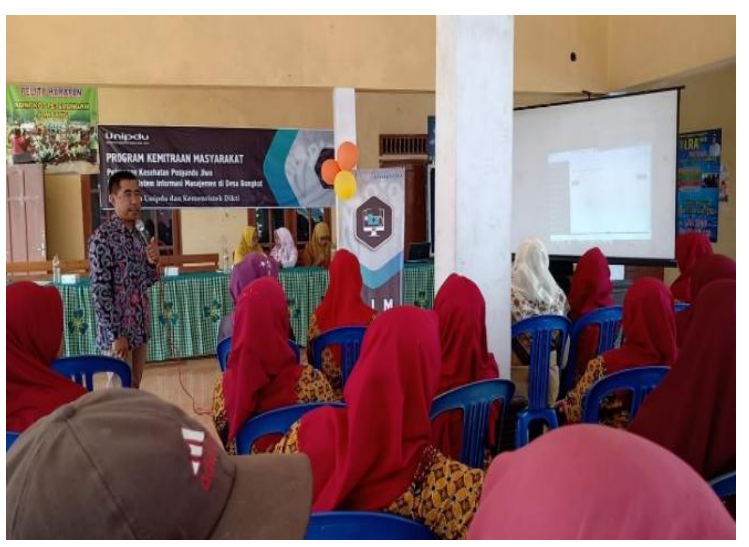

Gambar 2. Sosialisai SIM Posyandu

Kegiatan posyandu jiwa dilakukan rutin setiap minggu ke empat di desa bongkot, dengan menyiapkan meja 1 sampai dengan meja 5, dan rata-rata waktu yang diperlukan setiap putaran hampir 5 - 10 menit setiap orang, terutama dimeja satu yaitu meja registrasi rata-rata waktu yang diperlukan lebih lama karena kader harus mencari daftar nama pasien ditumpukan kartu sehat jiwa. Sehingga pasien banyak mengantri di meja satu, selain itu kartu tersebut kalau sudah lama resiko robek dan harus mengganti yang baru, kader memerlukan dana tambahan untuk pengadaan kartu tersebut, selain itu riwayat data penyakit pasien tidak dapat disimpan. Namun setelah adanya aplikasi SIM posyandu kesehatan jiwa proses registrasi tidak membutuhkan waktu lama hanya 1 menit daftar nama pasien dapat muncul semua, kader dapat memilih nama pasien yang ada di data presensi. Selanjutnya memilih gejala yang masih dirasakan pasien, kemudian akan muncul jenis gangguan yang dialami pasien, sehingga muncul 


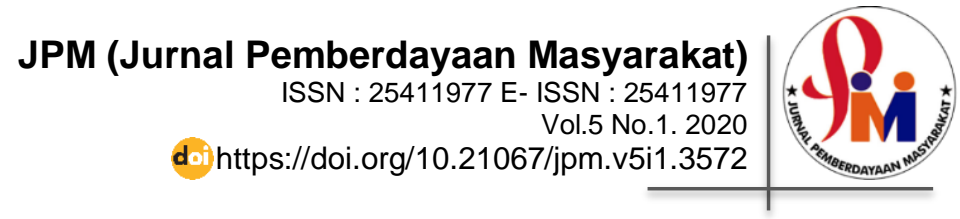

rekomendasi untuk tindakan keperawatan berikutnya, setelah data tersimpan kemudian kader memilih ketrampilan yang akan dilatih (Sutini, 2014). Setelah pasien direhab dan dilatih beberapa ketrampilan, hasil dari karya pasien dapat di tampilkan di galeri disertai dengan harga barang jualnya. Media ini merupakan cara efesien untuk promosi dan menambah pemasukan pasien dari hasil penjulan produk ketrampilan.

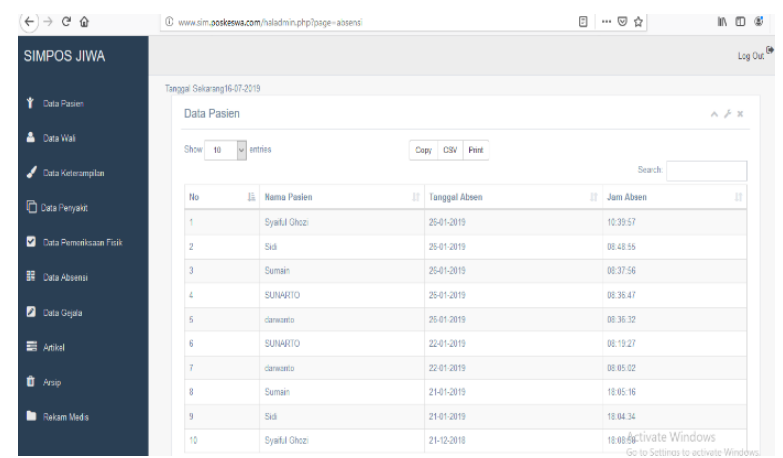

Gambar 3. Fitur data pasien pada SIM posyandu

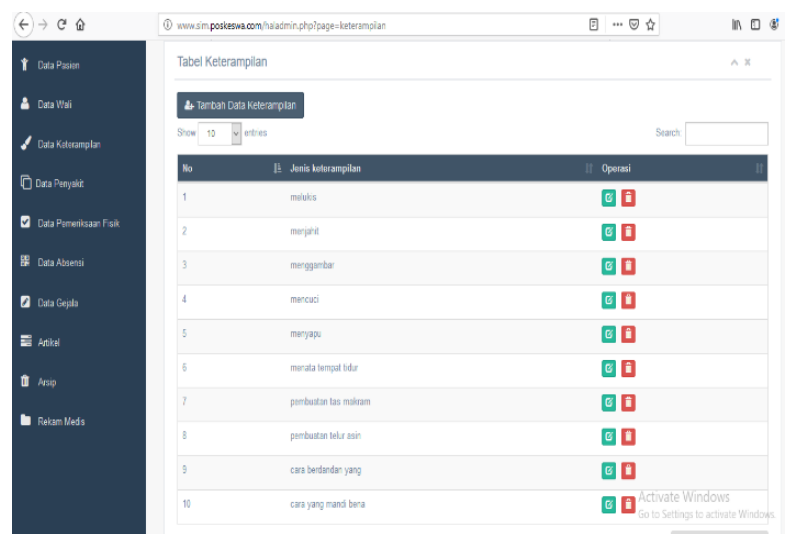

Gambar 4. Fitur menampilkan daftar gejala dan riwayat penyakit pasien

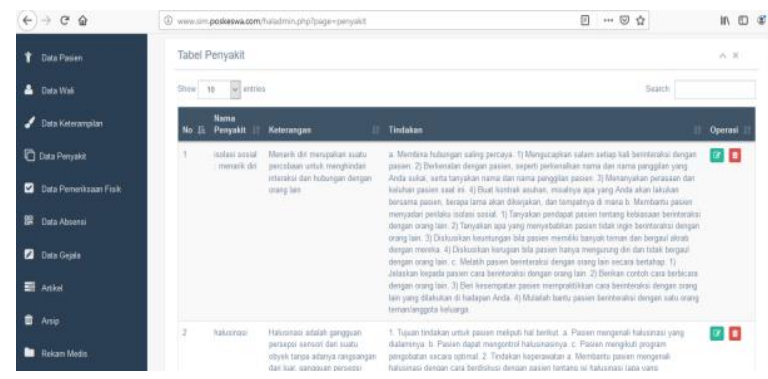

Gambar 5. Fitur yang menampilkan daftar ketrampilan yang akan dilatih

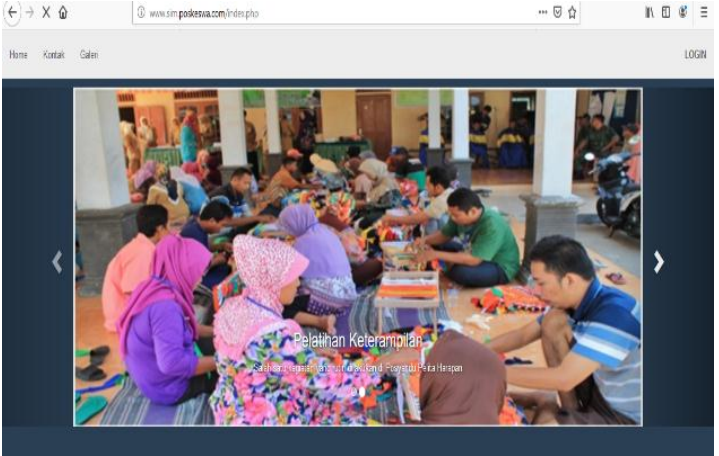

Gambar 6. Display karya ODGJ

Peserta dan menilai kemampuan setiap peserta. Saat pelaksanaan uji coba semua kader dapat menjalankan aplikasi tersebut dengan mudah, kader menggunakan handphonenya sendiri-sendiri untuk mengakses web posyandu jiwa dengan alamat: www.poskeswa.com dan semua dapat login dengan menggunakan pasword yang diberikan. Semua kader mengikuti arahan dan panduan yang diberikan oleh tim abdimas, mereka dapat menambahkan daftar pasien baru, melihat riwayat peyakit pasien dan melihat tanda gejala yang dialami pasien gangguan jiwa (Sulaiman, 2018). Kader sangat antusias dengan progam baru SIM posyandu, berdasarkan pengalaman kader bahwa aplikasi ini sangat efesien dan mudah untuk digunakan. Selain itu karena aplikai ini berbasis online, sewaktu-waktu jika kader memerlukan data pasien tidak perlu datang ke pustu untuk melihat KMSJ pasien, melainkan cukup membuka alamat webnya dimanapun berada.

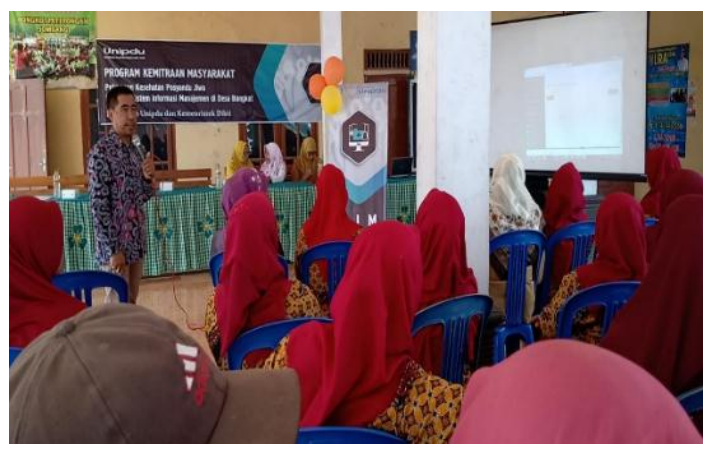

Gambar 7. Pelatihan SIM posyandu jiwa pada kader 


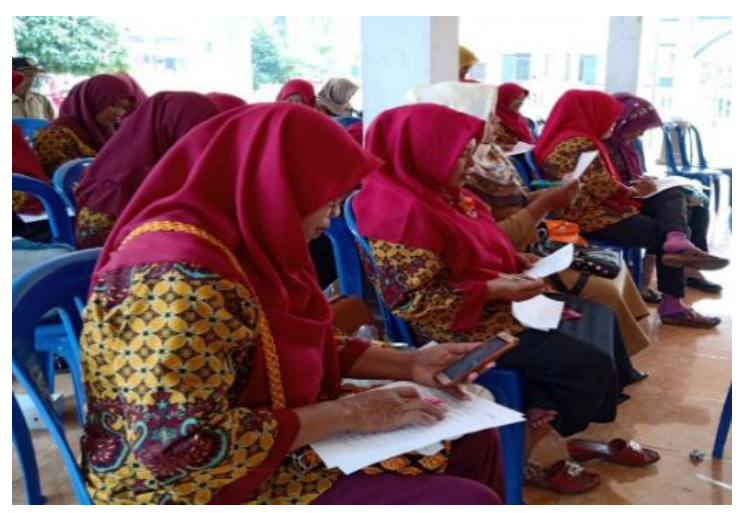

Gambar 8. Pengisian kuesioner

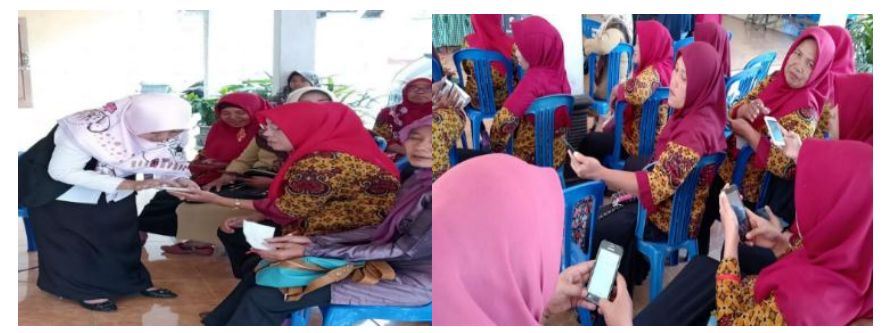

Gambar 9. Pengisian kuesioner

\section{Kegiatan Pendampingan Pelaksanaan SIM Posyandu Kesehatan Jiwa}

Kader melaksanakan posyandu jiwa dengan menerapkan aplikasi SIM, kegiatan ini dilaksanakan pada tanggal 22 Juli 2019 jam 08.00 WIB di Desa Bongkot. Peserta yang hadir sebanyak 40 orang. Pelaksanaan posyandu di dampingi oleh tim abdimas. Peserta diharapkan duduk dan satu persatu maju menuju meja registrasi untuk update data dan scane wajah, setelah itu pasien akan mendapat kode barcord yang tertera pada kartu peserta posyandu, selanjutnya memasukan hasil pemeriksaan TD, TB, dan BB kemudian kader menanyakan gejala yang muncul pada pasien dengan mencentang beberapa gejala yang sudah ada di daftar sistem tersebut, jika sudah kader klik hitung maka muncul dalam daftar rekomendasi masalah gangguan jiwa yang dialami pasien saat ini (Fairuzahida, 2017; Prasetyo \& Budiman, 2017).

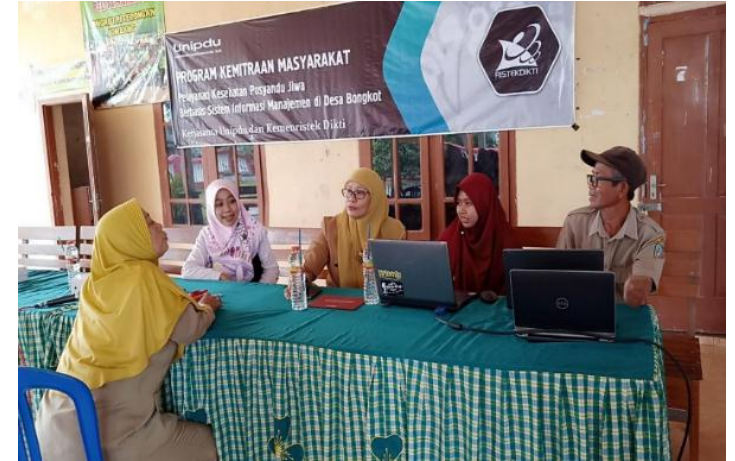

Gambar 10. Pendampingan Proses pelaksanaan posyandu jiwa dengan menggunakan SIM

Selanjutnya kader menanyakan ketrampilan yang sudah dilatih bulan sebelumnya, setelah itu memilihkan lagi jadwal kegiatan yang harus dilatih oleh pasien dengan mencentang daftar ketrampilan yang tertera di sistem tersebut. Dan jika pasien masih mengalami gejala yang sama dan tidak melatih ketrampilan yang dijadwalkan sebelumnya. Maka kader klik daftar saran rekomendasi untuk intervensi berikutnya dan melaporkan pada petugas kesehatan terkait gejala yang masih dialami oleh

pasien. Sehingga penanganan dapat diberikan dengan cepat dan tepat baik dengan farmaka maupun non farmaka seperti melatih SP pada pasien (Sutini, 2014).

Seluruh kegiatan posyandu dengan berbasis SIM dapat berjalan dengan efektik seluruh proses input data sampai dengan melatih ketrampilan menghabiskan waktu kurang lebih 80 menit dengan jumlah 40 orang. Sebelum menggunakan aplikasi ini waktu yang diperlukan saat kegiatan posyandu kurang lebih skitar 120 menit dengan jumlah peserta yang sama. Selain waktu yang lebih cepat, SIM posyandu dapat menyimpan semua daftar riwayat penyakit pasien sehingga terjaga keamanannya dan tidak lagi takut hilang (Roifah, 2017). 
Sehingga kader maupun petugas kesehatan akan mudah memantu status kesehatan pasien dengan mudah, Karena sistim ini berbasis online tidak perlu datang ke pustu mencari daftar pengunjung dan melihat buku catatan obat pasien, cukup petugas kesehatan masuk ke laman web www.poskeswa.com. Aplikasi ini juga memberikan akses pada keluarga untuk melihat status perkembangan keluarganya dengan memberikan pasword dan username pada keluarga yang menjadi wali dari pasien tersebut. Jika keluarga menginginkan daftar riwayat pasien secara tertulis, maka file data tersebut dapat dicetak dengan menggunakan print out.

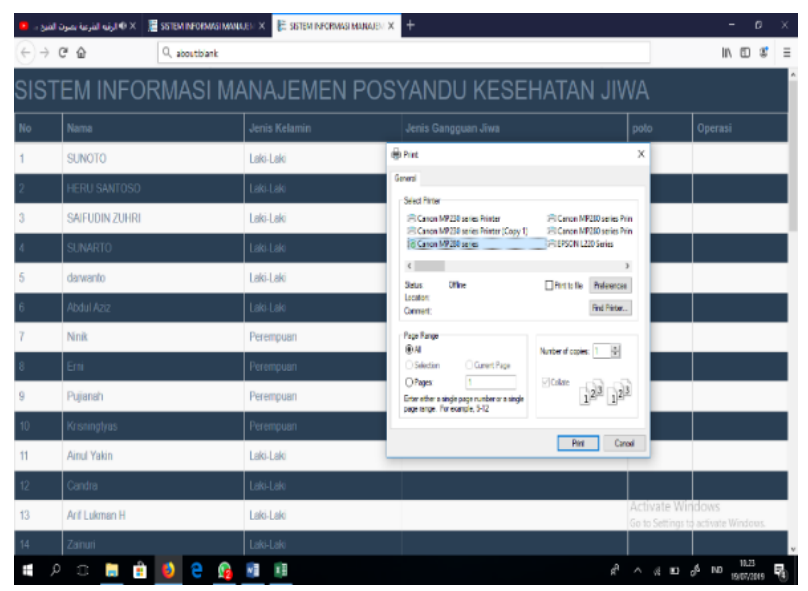

Gambar 10. Proses cetak data pasien

\section{Simpulan}

\section{PENUTUP}

Bentuk pengabdian ini dilakukan dalam rangka berperan serta dalam meningkatkan pelayanan kesehatan dan produktifitas ex ODGJ di Desa Bongkot. Keberhasilan dari kegiatan ini karena kerjasama dan dukungan dari Unipdu, PKM Dukuh Klopo, Kepala desa dan warga desa Bongkot Kecamatan Peterongan.

\section{Saran}

Kegiatan pengabdian ini untuk tetap diintegrasikan dalam kegiatan tridarma perguruan tinggi baik pengajaran, penelitian, dan pengabdian masyarakat sebagai upaya meningkatkan kesehatan orang dengan gangguan jiwa. Kegiatan ini dapat meningkatkan pelayanan kesehatan perlu dilakukan merata disemua kecamatan di Kabupaten Jombang. dapat berkelanjutan pada seluruh posyandu kesehatan jiwa.

\section{Ucapan Terimakasih}

Penghargaan dan rasa terima kasih kepada Direktur Riset dan Pengabdian Masyarakat, Dirjen Penguatan Riset dan Pengembangan, Kementrian Riset, Tehnologi dan Pendidikan Tinggi, yang telah membiayai Progam Kemitraan Masyarakat dengan judul "SIM Posyandu Kesehatan Jiwa"

\section{E. DAFTAR PUSTAKA}

Fairuzahida, N.N. 2017. Family Behavior of Nurture Mental Disorders in Kanigoro Blitar. J. Ners Dan Kebidanan J. Ners Midwifery. Vol. 4. No. 3. pp. 228234, Dec.

Mulyani, W. dan Purnama, B.E. 2015. Pembangunan Sistem Informasi Data Balita Pada Posyandu Desa Ploso Kecamatan Punung Kabupaten Pacitan. Speed - Sentra Penelit. Eng. Dan Edukasi. Vol. 7. No. 2.

Prasetyo, T.F. dan Budiman, A.Y. 2017. Perancangan Sistem Informasi Gizi Balita di Posyandu Berbasis Desktop Menggunakan Metode 
RAD (Rappid Application

Development) dengan

Menggunakan Netbeans dan

Database MySQL," INFOTECH J.

Vol. 3. No. 1.

Roifah, I. 2017. Peningkatan Kualitas Hidup Penderita Kusta dengan Menggunakan Metode Self Help Group (SHG). J. Ilmu Kesehatan. Vol. 6. No. 1. p. 8.

Sholihah, N. dan Kusumadewi. S. 2015. Sistem Informasi Posyandu Kesehatan Ibu dan Anak. Pros. SNATIF. Vol. 1. pp. 207-214.

Sulaiman, M.R. 2018. Dokter Jiwa Tekankan Besarnya Peran Keluarga dalam Upaya Pemulihan ODGJ. https://health.detik.com/beritadetikhealth/d-3887490/dokter-jiwatekankan-besarnya-peran-keluargadalam-upaya-pemulihan-odgj.

[Accessed: 22-Aug-2018].

Sutini, T., Keliat, B.A. dan Gayatri. D. 2014. Pengaruh Terapi Self-Help Group terhadap Koping Keluarga dengan Anak Retardasi Mental. Vol. 2. p. 8 .

Yusuf, R. F. Pk. dan Nihayati. H.E. 2015. Keperawatan Kesehatan Jiwa. Jagakarsa. Jakarta Selatan: Salemba Medika. 